\title{
EL HITO OLÍMPICO DE NICOLÁS MASSÚ Y DEL TENIS CHILENO EN LOS JUEGOS OLÍMPICOS DE ATENAS 2004: SU IMPACTO EN LA IDENTIDAD NACIONAL DE CHILE
}

\author{
Javier Alonso Medina Ramírez \\ Colegio Internacional SEK Austral (Chile) \\ javier.medinar@gmail.com \\ Ma Eugenia Martínez-Gorroño \\ Universidad Autónoma de Madrid (España) \\ eugenia.martinez@uam.es
}

Fecha de recepción: octubre 2017

Fecha de aceptación: junio 2018

DOI: $\underline{\text { http://doi.org/10.15366/citius2018.11.2.004 }}$

\section{Resumen:}

El presente artículo ofrece el resultado del trabajo de investigación histórica realizado en torno a la participación del equipo chileno masculino de tenis en los Juegos Olímpicos de Atenas 2004. Se reconstruyen como antecedentes las circunstancias y evolución deportiva de Nicolás Massú realizando su Historia de Vida deportiva hasta que alcanzó el nivel que le permitió su participación olímpica. En las jornadas de tenis de los Juegos, se ha recuperado el desarrollo y evolución de los partidos disputados por el equipo masculino de tenis chileno durante los días que se celebraron los encuentros, así como los hechos de las circunstancias y los hitos históricos que supusieron la medalla de oro obtenida por Nicolás Massú en el torneo individual y la segunda medalla que consiguió junto con su compañero Fernando González. Igualmente se rescata la memoria histórica de la percepción e influencia que aquellos hechos tuvieron en los ciudadanos de a pie chilenos a través del testimonio de fuentes orales chilenas contemporáneas de aquellos eventos deportivos. Sus relatos se han contrastado con la información que ofreció la prensa chilena, a fin de analizar la influencia, el sentido y la orientación del impacto que alcanzaron aquellos éxitos deportivos en los aspectos relacionados con la unidad, la identidad y la autoestima nacional.

Palabras clave: Juegos Olímpicos, Tenis, Equipo Olímpico de Chile, Nicolás Massú, Fernando González.

Title: THE OLYMPIC LADMARK OF NICOLÁS MASSÚ AND THE CHILEAN TENNIS IN THE 2004 OLYMPIC GAMES IN ATHENS: ITS IMPACT ON CHILEAN NATIONAL IDENTITY

\begin{abstract}
:
This article offers the result of the historical research work carried out around the participation of the Chilean men's tennis team at the Olympic Games in Athens 2004. It reconstructs as background, the many circumstances and sport evolution of Nicolás Massú carrying out a Sporting Life History until it reached the level that allowed him his Olympic participation. At the Games tennis days, the development and evolution of the matches played by the Chilean men's tennis team during the days that the matches were held, as well as the facts of the circumstances and the historical milestones that represented the gold medal obtained by Nicolás Massú in the individual tournament and the second medal he won along with his teammate Fernando González. Likewise, the historical memory of the perception and influence that those events had on Chilean citizens is recovered through the testimony of contemporary Chilean oral sources of those sporting events. Their stories have been contrasted with the information offered by the Chilean press, in order to analyse the influence, meaning and orientation of the impact achieved by those sporting successes in aspects related to unity, identity and national self-esteem.
\end{abstract}


Key words: Olympic Game, Tennis, Chilean Olympic team, Nicolás Massú, Fernando González.

\section{Introducción}

En las sociedades actuales, muchos acontecimientos deportivos desempeñan un papel crucial en la historia de los países e interfieren en forma definitiva en la idiosincrasia, la autoestima y las formas de sentir la nacionalidad y el orgullo de pertenencia a un estado. El deporte es uno de los elementos de cohesión nacional que se manifiesta y queda patente en los diferentes grupos sociales y que hoy puede observarse a partir de los medios de comunicación de forma clara. La evidencia de esta circunstancia es el motivo por el que, a nivel político, el deporte y las competiciones deportivas son utilizados por los poderes políticos $\mathrm{y}$, en este sentido, también han sido estudiadas las diferentes circunstancias que les han convertido en distintos momentos en hitos históricos en diferentes países.

\section{Objeto de estudio}

El presente trabajo se ha centrado en conocer la trayectoria deportiva y olímpica del tenista chileno Nicolás Massú, a fin de comprender las circunstancias del hito histórico que supuso su éxito en los Juegos Olímpicos celebrados en Atenas 2004 y analizar la influencia que aquel resultado tuvo en la elevación de la autoestima y la identidad nacional de los chilenos. Aquel hecho histórico supuso que, por primera vez en la historia, un deportista chileno consiguiera dos medallas de oro en una misma edición de unos Juegos Olímpicos. Podemos afirmar que aquellas circunstancias sirvieron, no sólo de propaganda positiva en todo el país, sino que fueron utilizadas y contribuyeron a la elevación de la autoestima nacional.

\section{Objetivos}

El objetivo principal de esta investigación es conocer el impacto y la influencia que supuso el hito olímpico de Nicolás Massú sobre la sociedad chilena en el sentido de su contribución a la elevación de la autoestima y la identidad nacional de los chilenos. Por ello procedimos a abordar los siguientes objetivos:

1. Conocer y reconstruir las circunstancias históricas de la trayectoria deportiva de Nicolás Massú hasta conseguir el nivel preciso para ser olímpico y optar a participar en la edición de los Juegos de Atenas 2004.

2. Conocer y reconstruir las circunstancias y los resultados de la participación de Nicolás Massú y de todo el equipo de tenis chileno masculino en los Juegos de Atenas 2004.

3. Analizar la influencia de los resultados exitosos de Nicolás Massú y del equipo chileno de tenis, a través de su repercusión en la prensa chilena, y el enfoque orientado a potenciar la identidad y la autoestima nacional del pueblo chileno.

4. Conocer, a partir de las fuentes orales, la influencia de los éxitos de Nicolás Massú en los Juegos de Atenas 2004 y su opinión sobre la influencia que tuvo para potenciar la identidad y la autoestima nacional del pueblo chileno. 


\section{Metodología}

Según se desprende del objeto de estudio, este trabajo ha supuesto una recuperación histórica de un fragmento de la Historia Contemporánea en la que aún hay fuentes vivas, por tanto es una investigación que se ubica metodológicamente como «Historia del Tiempo Presente» (Bédarida, 1998). Teniendo en cuenta, que la metodología estuvo condicionada por esta circunstancia, y siguiendo las afirmaciones de Adbón Mateos, es preciso tener en cuenta que

«La fuente oral resulta una excelente vía de acceso a las nociones de memoria histórica colectiva y cultura política en la historia del tiempo presente. Su importancia se acrecienta en la medida en que el pasado reciente no haya cristalizado todavía como memoria autobiográfica. La debilidad de la literatura autobiográfica para el tiempo más inmediato solamente puede suplirse con la fuente oral. Acceder a la experiencia vivida autobiográfica y colectiva de un miembro de un grupo social o asociación humana en el tiempo presente depende, en buena medida, del recurso a la fuente oral» (Abdón Mateos, 1998, p.3).

Por ello, hemos recogido información a partir de tres fuentes orales primarias. Se trata de tres profesores chilenos de Educación Física, que por su edad actual fueron contemporáneos a los hechos deportivos objeto de estudio, y que, por su profesión, están cercanos a los ámbitos deportivos y próximos a los fenómenos sociales que los resultados olímpicos suponen sobre los grupos de población. Así pues, siguiendo a Soto Gamboa, el investigador de la Historia del Tiempo Presente, «tiene la posibilidad de apreciar y observar las mentalidades, la percepción de los contemporáneos sobre el tema y sus propias vivencias» (Soto Gamboa, 2004, p.137).

Por otra parte, también hemos utilizado diferentes fuentes hemerográficas. Se trata de diarios y publicaciones periódicas chilenas que en aquellos momentos incluyeron noticias relativas a aquellos triunfos deportivos. Seleccionamos para ello los diarios de la época que se dirigían a diferentes sectores sociales de Chile. Así hemos recuperado y contrastado la información de las noticias relativas a los resultados olímpicos de Nicolas Massú y del equipo chileno masculino de tenis en Atenas 2004 de los siguientes diarios: Periódico El Mercurio, Periódico La Tercera, Periódico Las Últimas Noticias, Periódico La Cuarta. Todos ellos en sus ediciones de enero a diciembre del año 2004. El diario Las Ultimas Noticias y el periódico La cuarta, con una orientación dirigida principalmente a un público más popular y de bajos recursos, son considerados los más populares. Los periódicos La Tercera y El Mercurio se consideran más conservadores y están dirigidos a los sectores sociales más elitistas y de mayores recursos.

Con las noticias seleccionadas que en dichos diarios recogieron información al respecto del objeto de estudio hemos procedido a un «Análisis documental». En este se han tenido en cuenta varios aspectos. En primer lugar, los datos meramente descriptivos que han sido útiles para la reconstrucción histórica de los hechos tal y como se fueron sucediendo, para configurar su «Historia de Vida deportiva» en la parte relacionada con los Juegos de Atenas 2004. En segundo lugar, el «análisis documental» también se centró en aspectos que, si bien pueden cuantificarse, también reflejaban la importancia que los diferentes diarios concedían a aquellos resultados olímpicos: la ubicación de la noticia en las páginas de los diarios, la cantidad de columnas, páginas y espacios que se le dedicaron, la inclusión de fotografías, la circunstancia de si la noticia fue «primera página» en algún momento, etc. Igualmente, el análisis también se centró en extraer y reflexionar en los aspectos cualitativos que ofrecían otros datos sobre la orientación nacionalista del resultado. Sobre la orientación que se confería al titular y al contenido, a fin de conocer si se orientaba a potenciar la elevación de la autoestima del pueblo chileno, si se enfocaban en paralelo aquellos éxitos deportivos como el triunfo de toda la nación, potenciando con ello aspectos como la 
cohesión nacional, o la contribución a crear una identidad nacional positiva en torno a aquellos éxitos de unos deportistas nacidos en Chile.

\section{El camino de Nicolás Massú al hito olímpico en Atenas 2004: Reconstrucción de su Historia de Vida deportiva}

Nicolás Massú Fried nació el 10 de octubre del año 1979 en la ciudad de Viña del Mar, en el seno de una familia chilena de origen palestino y judío. Massú comenzó a incursionar en el mundo del tenis a los 6 años de edad gracias a su abuelo Ladislao Fried, de origen húngaro, quien llegó a Chile junto con su esposa Veronika Vegvari, escapando del sufrimiento del Holocausto. Fue por tanto Don Ladislao Fried, quien infundió a Nicolás la pasión por el tenis. Le matriculó en el Club de Tenis Unión, de la ciudad de Viña del Mar donde Massú conoció a su primer entrenador: Enrique Cortés. Cortés en una entrevista realizada para el periódico La Tercera (2013), recordaba un episodio relacionado con el carácter que desde un principio observó en Nicolás y que le hizo entender que estaba frente a un jugador diferente:

«Él quería ganar siempre. Una prueba de ello es que siendo muy chiquitito yo le tiraba la pelota y no llegaba. Ahí la tomaba con la mano, se la ponía en la raqueta y me la tiraba al otro lado. Luego me decía: Punto mío, punto mío. Ahí me di cuenta de su mentalidad». (La Tercera, 27/08/2013).

Poco después de cumplir 11 años, Massú ingresó a la Academia ANTZ, en el complejo Valle Dorado, ubicado en el pueblo de Villa Alemana, localidad que se encuentra aproximadamente a 20 kilómetros de su ciudad natal Viña del Mar. En dicha academia, conoció a uno de los entrenadores más importantes de su carrera, Leonardo Zuleta, quien años más tarde, se convirtió en el capitán del equipo chileno de Copa Davis.

Junto a Leonardo Zuleta, Massú realizó su primera gira al extranjero. En ella logró el triunfo en su primer torneo e inició un camino exitoso en la categoría Junior, con la consagración que le supuso la obtención de títulos como la corona del Orange Bowl en individuales, Wimbledon y el US Open en la modalidad de dobles. En Wimbledon se consagró como campeón junto al tenista peruano Luis Horna, mientras que en el US Open fue ganador junto a su amigo de la infancia, el tenista nacional Fernando González, con quien posteriormente formó pareja en dúplex en el equipo chileno.

Nicolás Massú finalizó su participación como tenista junior siendo el $\mathrm{n}^{\circ} 1$ en la modalidad de dobles y $5^{\circ}$ en la modalidad individual del ranking mundial.

Nicolás Massú se estrenó en el circuito profesional de la ATP en el año 1998. Durante los dos primeros años en el circuito profesional, logró coronarse como campeón de torneos de menor nivel como «Futures y Challengers» en Europa y América del Sur. Sin embargo, los logros más importantes que alcanzó fueron dos: primero el hecho de convertirse en la segunda raqueta de su país y, después, el de terminar su segundo año dentro de los 100 mejores tenistas del mundo, según el ranking ATP.

En el año 2000 se produjo el primer acercamiento de Massú al Olimpismo, siendo el abanderado chileno en los Juegos Olímpicos de Sídney 2000. Aquel suceso marcó fuertemente al tenista chileno, ya que reforzó su convicción de que jugar representando a su país, era más importante que su carrera profesional. Durante los siguientes dos años, Massú experimentó una paralización en el progreso que venía demostrando. Bajó del ranking de los 100 mejores tenistas del mundo a nivel internacional, y fue sobrepasado por el tenista Fernando González a nivel nacional. Fue por tanto calificado como el tercer tenista chileno. Sin embargo, no todo fue negativo y a

Citius, Altius, Fortius Volumen 11 ne 2. Noviembre, 2018. ISNN. 2340-9886.

http://doi.org//10.15366/eitius2018.11.2 
mediados del año 2002, Nicolás Massú logró ganar su primer torneo ATP como profesional. Aquella circunstancia le impulsó nuevamente a colocarse dentro de los mejores 100 tenistas del mundo, finalizando la temporada en el $56^{\circ}$ lugar del ranking ATP.

El 2003 fue uno de los años que hemos encontrado en la «Historia de Vida deportiva» de Massú como de los más exitosos como tenista profesional. Durante aquel año logró consagrarse campeón del ATP de Amersfoort y Palermo y además fue finalista de grandes torneos como Máster Series de Madrid, y los ATP de Kitzbuhel y Bucarest. Pero sin lugar a duda, el logro más importante obtenido aquel año por Massú, fue la obtención del World Team Cup de Dusseldorf, en compañía de los tenistas nacionales Fernando González y Marcelo Ríos. Aquel triunfo suponía que el equipo chileno integrado por Massú, González y Ríos conseguía un primer hito histórico nacional para el deporte de su país, ya que era el primer triunfo internacional como país en la historia del tenis chileno.

El año 2004 podemos calificarle como el año más importante en la carrera tenística de Nicolás Massú, como también del deporte olímpico chileno. A comienzos del año, aquel equipo nacional formado por Massú, González y García, obtuvo por segundo año consecutivo el título World Team Cup en Dusseldorf. Posteriormente Massú ganó el torneo de Kitzbuhel en Austria y se preparó para disputar los Juegos Olímpicos de Atenas 2004.

\section{Desarrollo, evolución y triunfos del equipo masculino de tenis chileno en los Juegos de Atenas 2004}

El tenis masculino en Atenas 2004 se disputó entre el domingo 15 y el domingo 22 de agosto, en el Centro Olímpico de tenis. Fue una semana intensa, en la cual por las mañanas se disputaron las pruebas individuales y por las tardes las pruebas de dobles. El equipo de tenis chileno estuvo representado por Nicolás Massú y Fernando González, clasificados como $14^{\circ}$ y $17^{\circ}$ en el ranking mundial individual, como también $69^{\circ}$ y $89^{\circ}$ en el ranking mundial de dobles. Ellos, junto con sus entrenadores, decidieron participar tanto en las pruebas individuales, como también en las pruebas de dobles.

El primer partido que disputó Nicolás Massú en la prueba individual fue frente al brasileño Gustavo Kuerten, ex número 1 del mundo. A pesar de que el brasileño era conocido por ser un tenista muy tenaz, sin embargo, Massú venció a Kuerten en tres sets, con los parciales 6-3, 5-7, 6-4. Horas más tarde hizo junto a Fernando González, su debut en la prueba de dobles, frente a la pareja de Bahamas: Mark Knowles y Mark Merklin, quienes por esos días se ubicaban en el séptimo lugar del ranking mundial de dobles de la ATP. La pareja chilena logró vencer en dos sets, con un marcador 7-5, 6-4 y así avanzaron a la siguiente fase del torneo olímpico.

Al día siguiente, Massú, en la prueba individual compitió con el estadounidense Vincent Spadea, a quien logró vencer en dos sets, con los parciales 6-3, 6-7 (4), 6-4, consiguiendo avanzar a la tercera ronda del certamen olímpico. En la jornada de la tarde, la pareja chilena se enfrentó al equipo argentino integrado por Gastón Etlis y Martín Rodríguez, consiguiendo un marcador de 6-3, 7-6 (2), lo que permitió a los chilenos avanzar a cuartos de final. Aquel hecho tuvo una repercusión importante en las noticias de la prensa chilena del momento, siendo destacada en todos los diarios.

A la mañana siguiente, Nicolás Massú se enfrentó al ruso Igor Adreev. El efecto de la fatiga acumulada por los compromisos anteriores comenzaba a hacer efecto sobre el tenista chileno; sin embargo, Nicolás logró vencer al tenista ruso en tres largos sets, y se preparó para competir por la tarde, junto a Fernando González, contra los hermanos estadounidenses Bob y Mike Bryan, que eran los números uno en el ranking mundial de la ATP, además de ser los favoritos para ganar el 
certamen olímpico. Horacio de la Peña, entrenador en ese periodo de Fernando González, recordaba aquel momento en el periódico La Tercera de la siguiente manera:

«A mi juicio, era un partido clave, fue el momento en que nos reunimos en el cuarto con Patricio Rodríguez, Nicolás Massú y Fernando González, y analizamos las posibilidades de privilegiar los singles para no seguir desgastándonos y perderlo todo, pero al final nos miramos y dijimos: Vamos por todo» (La Tercera, 27/08/2013).

La tarde del 18 de agosto del año 2004, la pareja chilena venció a los hermanos Bryan en dos sets, con los resultados parciales de 7-5, 6-4, logrando, de esta manera, acceder a una semifinal olímpica, aspecto que ya era por sí mismo un hito histórico para el deporte chileno, ya que nunca antes un equipo de tenis de Chile había conseguido estar en una semifinal olímpica.

Por su parte, Fernando González había avanzado de la misma manera que Massú en la prueba individual, comenzando a generar expectación en Chile, por una posible final individual entre ambos.

El jueves 19 de agosto Massú se enfrentó al experimentado tenista español Carlos Moyá, derrotándolo por los parciales 6-2, 7-5. Con ello alcanzaba la semifinal del certamen olímpico, y se aseguraba, al menos, la medalla de bronce, debido a que Fernando González, como hemos dicho, había también avanzado paralelamente a la semifinal.

Por la tarde, la pareja chilena con claras muestras de fatiga, según reflejaba la prensa, se enfrentó a la dupla croata compuesta por Ivan Ljubicic y Mario Ancic que se situaban en aquel momento como terceros en el ranking mundial. Sin embargo, los chilenos quedaron vencedores con los resultados parciales de: 7-5, 4-6, 6-4. La prensa destacó especialmente aquel triunfo olímpico informando en sus noticias que suponía alcanzar la primera final de la historia del tenis olímpico chileno y que llevaba consigo la posibilidad de alcanzar una primera presea dorada para el país, al avanzar a una histórica final por equipos.

El viernes 20 de agosto solo tuvieron lugar dos semifinales de las pruebas individuales, en las que se encontraban los dos tenistas chilenos. Nicolás Massú se enfrentó al estadounidense Taylor Dent, al cual logró vencer en dos sets, con los parciales: 7-6(5), 6-1. Con aquel triunfo se convirtió en el primer finalista de Atenas 2004, siendo destacado por la prensa chilena como la esperanza para que Chile alcanzara la medalla de oro individual. En paralelo al juego de Massú, se produjo el enfrentamiento de Fernando González con el estadounidense Mardy Fish. El partido estaba siendo cómodamente dominado por el tenista chileno, cuando, a mediados de la disputa del segundo set, Fernando González sufrió un esguince de tobillo, que le impidió seguir jugando con normalidad, provocando su derrota.

El sábado 21 de agosto del año 2004, fue una fecha especial para la historia del olimpismo chileno En la jornada de la mañana, Fernando González disputaba la medalla de bronce frente al estadounidense Tylor Dent, a pesar de no haber recuperado la lesión que había sufrido el día anterior. Tras un extenuante partido de 2 horas de duración, logró vencer al estadounidense. Aquel triunfo le suponía una medalla de bronce en el torneo de tenis individual masculino.

Cuatro horas después, Massú y González se enfrentaron a la pareja alemana conformada por Nicolas Kiefer y Reiner Shuttler que, sin embargo, por las circunstancias de los resultados del programa establecido, habían tenido dos días de descanso absoluto antes de aquel encuentro. El resultado de aquel partido suponía la obtención de la medalla de oro en la prueba de dobles. La situación igualada llevó al encuentro al cuarto set, con 4 puntos de partido en contra del equipo 
chileno que, a pesar de todo, supo sobrellevar, para luego conseguir el triunfo. La pareja chilena logró coronarse campeona y con ello, según se anunció en la prensa, Chile obtuvo la primera medalla de oro de su historia en unos Juegos Olímpicos. La prensa deportiva de todo el país ofreció la noticia de la celebración del triunfo de Massú y González en dobles, por la que el pueblo chileno se volcó a la calle a celebrar que, por primera vez en la historia, el himno patrio sonaba en la ceremonia de los Juegos Olímpicos.

El domingo 22 de agosto un extenuado Nicolás Massú disputó la final individual del tenis masculino frente al estadounidense Mardy Fish. El partido se prolongó por más de tres horas, al final de las cuales el tenista chileno logró coronarse como campeón olímpico del tenis individual masculino tras derrotar al norteamericano por los parciales 6-3, 3-6, 2-6, 6-3, 6-4. Con ello, según destacaba la prensa del momento, lograba entrar en la historia del certamen olímpico con letras doradas, siendo el único tenista en ganar las preseas doradas de tenis en las categorías individual y dobles, en el mismo certamen olímpico. ${ }^{1}$ También suponía la segunda medalla de oro olímpica del deporte chileno.

\section{El impacto del hito olímpico del equipo chileno de tenis en los Juegos de Atenas 2004 en la ciudadanía chilena a partir del recuerdo de tres docentes del área de educación física y del deporte}

Con respecto al impacto y la gran expectación que supuso entre la población chilena la participación olímpica de Nicolás Massú, Matías Vergara ${ }^{2}$ nos decía en la entrevista que con él mantuvimos, que la semana en la que se desarrollaron los partidos, coincidió con una semana escolar. Recordaba especialmente aquella circunstancia porque él tenía 15 años y cursaba estudios de secundaria y, teniendo en cuenta la expectación que se vivía entre la población, recordaba que en más de una ocasión tuvo que solicitar permiso para poder ver la transmisión de los partidos junto a sus compañeros en horario de clases. Matías reflexionaba sobre sus recuerdos relativos a la participación de los tenistas chilenos en el certamen olímpico y que en principio no se veía nunca con la posibilidad de que Nicolás Massú pudiese optar por el oro olímpico, pues se informaba de que en el certamen se encontraban los más importantes tenistas, entre los que recordaba a Roger Federer y Andy Roddick. Por otra parte, creía recordar que las posibilidades que la población veía con respecto a los éxitos del tenis chileno podrían llegar de la mano del tenista nacional Fernando González y no de Nicolás Massú.

Matías Vergara recordaba haber vivido junto a su familia las finales, tanto del partido individual como del partido de dobles. Aquellos recuerdos trajeron a su memoria la emoción hasta las lágrimas que les llegó a suscitar el desenlace de las finales. Matías rememoraba la emoción de que, tras la entrega de las medallas, la gente saliera a la calle a celebrar aquella victoria, la cual se veía como un éxito de todos y era motivo de alegría conjunta. Durante la entrevista que mantuvimos con él, reflexionaba sobre aquella respuesta de la gente, atribuyéndola a la generación de un sentimiento de empatía con el esfuerzo y la pasión con la cual se desempeñaron los tenistas nacionales.

\footnotetext{
${ }^{1}$ Nos parece significativo señalar que, en la fecha de hoy, grandes exponentes del tenis mundial como Rafael Nadal, Novak Dokovic, Roger Federer, Andy Murray, no han conseguido igualar la hazaña olímpica alcanzada por Nicolás Massú en Atenas 2004. Hasta Río 2016, esa hazaña sigue sin haberse igualado.

${ }^{2}$ Matías Vergara Soria, Profesor de Educación Física de nacionalidad chilena, que ha sido una de las tres fuentes orales que ha prestado su testimonio para la realización de este trabajo.
} 
Respecto de lo sucedido en la sociedad chilena, tras el logro de las medallas de oro, el profesor Vergara sostenía en sus reflexiones que, a partir de aquel suceso, la sociedad chilena comenzó a forjar un orgullo por la representación nacional, junto con el inicio de la formación de una mentalidad ganadora. También consideraba que aquel triunfo fue un trampolín para los actuales deportistas, quienes pudieron presenciar cómo el talento sale a relucir con trabajo, sacrificio y esfuerzo. Para Matías, el triunfo de Massú implicó que la sociedad chilena comenzara a interesarse más por los resultados deportivos de los Juegos Sudamericanos, Panamericanos y los Mundiales, así como por todos los eventos internacionales en los cuales existe un representante nacional.

Por último, consideraba que la mentalidad actual del pueblo chileno, como también la de sus deportistas, está influenciada por aquel primer hito olímpico y, sobre todo, por el mensaje que generó Nicolás Massú y se hizo patente tras la obtención de las medallas: en la vida, nada es imposible. Cree que este mensaje ha quedado arraigado en el corazón de la sociedad chilena, y que se ha ido potenciado en los últimos años, a través de los triunfos deportivos obtenidos por el futbol.

Nuestro segundo entrevistado, el Profesor chileno de Educación Física y Salud, Álvaro Lagos Lagos, Licenciado en la Universidad Andrés Bello de Chile, nos contaba que en el año 2004 tenía tan solo 12 años y cursaba estudios primarios. Recordaba que quizás por su edad, el comienzo de los Juegos Olímpicos no era un evento tan llamativo como lo es para los actuales niños chilenos. Sin embargo, con la repercusión mediática que alcanzaron por los resultados que iban obteniendo, según transcurrían los días, fue imposible no ver algún partido de Massú para luego comentarlo con sus compañeros y amigos. Recordaba especialmente que las finales fueron muy largas y emocionantes. A pesar de sus pocos años, rememoraba que se sintió muy orgullo por ser chileno y que, en el momento de escuchar el himno nacional en la ceremonia de entrega de premios, sus emociones estaban a flor de piel. Nos comentaba que después de aquel hito olímpico, él junto con todos sus compañeros y amigos, solo pensaban y soñaban con lograr alguna hazaña deportiva, al igual que la realizada por Nicolás Massú.

Para Álvaro, uno de los hechos que más le impactó, tras aquel triunfo olímpico, fue el recibimiento que hizo el Presidente de la República a los tenistas nacionales, quienes luego realizaron un saludo desde el balcón de la Casa de Gobierno a centenares de chilenos que se habían reunido y esperaban para agradecerles el triunfo olímpico obtenido.

De acuerdo con su visión de los hechos, comparte la opinión con Matías Vergara, al sentir que, tras aquel primer triunfo olímpico, los chilenos se sintieron orgullosos y representados por la pasión y esfuerzo demostrado por Nicolás Massú y Fernando González. Además, sostuvo que gran parte de la obtención de los nuevos triunfos deportivos posteriores, se debe al cambio de la mentalidad y convicción de los deportistas chilenos con respecto a la posibilidad de ganar eventos internacionales, que comenzó a generarse tras la hazaña tenística realizada en Atenas 2004.

Por último, Álvaro nos comentaba que, en su opinión, luego del hito olímpico obtenido por Nicolás Massú en Atenas 2004, la disciplina del tenis olímpico tomó otro significado para los tenistas profesionales quienes, en la actualidad, miran de otra manera el certamen olímpico. Opinaba que esto se puede observar, en la intención de los grandes tenistas actuales como Roger Federer, Andy Murray, Rafael Nadal y Novak Djokovic, etc., quienes, en los posteriores Juegos Olímpicos, han disputado tanto la prueba individual como la de dobles, con la intención de igualar la hazaña realizada por Nicolás Massú.

La tercera fuente oral que entrevistamos fue el Profesor chileno de Educación Física y Salud, Edson García Díaz actual estudiante del Máster de Ciencias de la Actividad Física y del 
Deporte en la Universidad Autónoma de Madrid. Cuando se produjo el hito del tenis chileno en Atenas 2004, Edson tenía 27 años y recordaba el triunfo olímpico de Nicolás Massú, como un gran acontecimiento en todo Chile, el cual sirvió para modificar una creencia popular que hacía referencia a «lo buenos que somos, pero nunca ganamos nada». El comienzo del proceso del tenis olímpico en Atenas 2004 lo vivió, como todo chileno, algo incrédulo al comienzo y, coincidiendo con el testimonio de Matías Vergara, con más esperanza en lo que podría hacer el tenista chileno Fernando González. Edson veía al equipo chileno de tenis con mayores posibilidades de obtener buenos resultados, en relación con los otros equipos de otras especialidades deportivas que confirmaban la delegación chilena. Este optimismo lo fundamentaba en la profesionalización de los tenistas, en desmedro de los otros equipos chilenos, que no presentaban el mismo nivel de profesionalización. Por consiguiente, veía que las posibilidades de conseguir algún resultado exitoso a través del tenis en los Juegos de Atenas 2004 no era algo utópico. Sin embargo, aseguraba que hasta las mejores expectativas fueron superadas por lo realizado por Massú y González.

Para Edson el hito olímpico influyó fuertemente en la sociedad chilena puesto que con ello se comprendió que el camino para lograr resultados deportivos era a través de la vía del esfuerzo y del sacrificio personal. La sociedad comprendió que, con dedicación, disciplina, esfuerzo, pasión y sacrificio, se puede lograr todo lo que se desea. Recordaba la gran repercusión mediática que se generó con el pasar de los días y el avance de los tenistas chilenos hasta la final. Afirmaba textualmente: «subió como la espuma». ${ }^{3}$ Sin embargo, una vez obtenidos los triunfos en Atenas y con el pasar los meses, la repercusión mediática disminuyó con la misma fuerza con la cual había subido.

Bajo su visión como profesional del deporte, en la actualidad, afirmaba que los actuales deportistas chilenos aprendieron, a través del hito olímpico de Atenas 2004, que, mediante el esfuerzo y el trabajo disciplinado, no existen resultados deportivos imposibles. También sostuvo que las nuevas generaciones de deportistas heredaron de los tenistas de Atenas 2004 la importancia de representar al país. Heredaron el sentimiento de que no existe un honor más importante que ser representante del propio país en alguna competición internacional.

En la opinión de Edson, no cabe duda de que existió un antes y un después en el deporte chileno tras el hito olímpico de Atenas 2004. Recordaba un dicho popular, «jugamos como nunca y perdimos como siempre». ${ }^{4}$ Aquella afirmación era muy habitual dentro de la sociedad chilena para hablar de los resultados deportivos. Y aseguraba que, hoy, ese dicho ya no sirve. Hoy la sociedad exige a los deportistas dar su mejor esfuerzo. No es suficiente con participar, ya que cuando se representa al país se debe dejar «la piel en la cancha» ${ }^{5}$ como lo hicieron los tenistas en Atenas 2004.

La opinión final de Edson y, como conclusión a través de su testimonio, podemos afirmar que el resultado obtenido por Nicolás Massú tuvo repercusión también en la política deportiva del país, en la creencia deportiva del pueblo chileno y en la sociedad en general, propiciando una nueva mentalidad por parte de la sociedad chilena para enfrentar los desafíos.

\footnotetext{
${ }^{3}$ De entrevista realizada a Edson García Díaz, profesor chileno del área de la Educación Física y salud, realizada en Madrid el día 20 de mayo del 2017.

${ }^{4}$ Ibidem.

${ }^{5}$ Ibidem.
} 


\section{La repercusión en la prensa chilena: Resultados del análisis documental de las fuentes hemerográficas}

Realizando una recuperación de la información ofrecida sobre el objeto de estudio de este trabajo en las diferentes fuentes hemerográficas ya señaladas, hemos podido conocer que previamente a la celebración de los Juegos Olímpicos de Atenas 2004, la prensa escrita presentaba las mayores expectativas, ante la participación olímpica del tenis masculino chileno, aspecto que se fundamentaba en la circunstancia de que a comienzos de ese mismo año, el equipo chileno de tenis con la presencia de Nicolás Massú y Fernando González, se habían coronado campeones de la Copa del Mundo por equipos en Dusseldorf.

Los datos recogidos tras el análisis de las noticias ofrecidas en los diarios de aquellas fechas nos ofrecen una cobertura que inicialmente se limitaba a las secciones deportivas. Sin embargo, con el pasar de los días y el avance de los chilenos a las siguientes fases, las noticias relacionadas con los tenistas comenzaron a aumentar a nivel cuantitativo y cualitativo. Después del paso a la tercera ronda en el torneo individual y el paso a cuartos de final en dobles, cuando los chilenos se enfrentaron a la pareja estadounidense que se encontraban en el primer lugar del ranking mundial de la ATP, los periódicos empezaron a citar aquellos avances del tenis chileno en los Juegos de Atenas en páginas que sobrepasaban la sección deportiva. Por otra parte, a nivel cualitativo la prensa comenzó a especular sobre una posible final individual integrada por los dos tenistas chilenos y también empezaba incluso a señalar la posibilidad de la obtención de una medalla en dobles.

Los diarios que principalmente daban cobertura en páginas centrales y portadas fueron el periódico Las Ultimas Noticias y el periódico La Cuarta, los cuales, como ya hemos indicado, están orientados principalmente a un público más popular. El resto de los periódicos, aumentaron la cobertura de los logros de los tenistas chilenos, aunque, sin embargo, se mantenía en la sección de deporte. Con el paso a la semifinal en individuales y final en dobles, las noticias, además de ir ocupando las páginas principales, comenzaron con alabanzas a aquellos resultados denominándolos como «La epopeya Griega» de los tenistas nacionales. Las especulaciones sobre una primera medalla de oro en una final individual entre nacionales comenzaron a ocupar portadas y páginas centrales y portadas de todos los periódicos. También empezaron a aparecer en los periódicos más populares entrevistas a familiares, compañeros y ex entrenadores de los tenistas.

El domingo 22 de agosto del año 2004, todos los periódicos nacionales presentaron una portada con la fotografía de los tenistas recibiendo la primera medalla de oro para Chile. El periódico Las Ultimas Noticias publicó en su portada la foto de la ceremonia de entrega de premios a los tenistas y el periódico La Cuarta tituló «Esto Jamás lo olvidaremos», situándolo en una portada especial de dos páginas, en la cual se puede apreciar el rostro de los tenistas, junto con el título «Feña y Nico son puro oro». El periódico El Mercurio, más conservador, presentó una fotografía de los tenistas abrazándose tras el punto final y tituló: «Lo mejor desde Melbourne 1956».

Las portadas de los periódicos siguieron reproduciendo la imagen de los tenistas nacionales, hasta el día 14 de septiembre del año 2014, ya que el día 13 de septiembre ambos tenistas fueron recibidos por el Presidente de la República, Don Ricardo Lagos Escobar, en el Palacio de la Moneda, tras haber llegado a Chile procedentes de Atenas. La influencia popular se pudo ver en el hecho de que los tenistas fueron acompañados desde el aeropuerto hasta el palacio de gobierno por un centenar de chilenos que salieron de sus casas para celebrar y agradecer el esfuerzo de Nicolás Massú y Fernando González. 


\section{Conclusiones}

En el recuerdo histórico de la sociedad chilena el año 2004 ha quedado especialmente marcado aquel éxito deportivo. Su rememoración suscitó tanto las ilusiones y los entusiasmos nacionales, como trajo a la memoria de las fuentes orales las múltiples celebraciones y conmemoraciones que les hicieron sentirse unidos de la mano de los triunfos de los tenistas nacionales, Nicolas Massú y Fernando González, en los Juegos de Atenas. El hecho de la obtención de la primera medalla de oro en unos Juegos Olímpicos por parte de un tenista chileno, Nicolás Massú, fue un hecho histórico que quedó grabado en la memoria colectiva e individual de los chilenos «de a pie», así como el hito del total de las tres medallas que supusieron los triunfos del tenis masculino de Juegos Olímpicos de Atenas 2004. Aquel hito histórico deportivo fue mencionado en los relatos como motivo de un sentimiento de la propia pertenencia a la nacionalidad chilena y la constatación de una circunstancia que propiciaba la unidad familiar y social del pueblo chileno. El 22 de agosto del año 2004, el tenista chileno Nicolás Massú se convirtió en el único tenista de la historia, en lograr ganar la medalla de oro en la categoría individual y dobles en una misma edición de los Juegos Olímpicos. Este hito deportivo histórico, influyó profundamente en la autoestima de los chilenos que celebraban como si se tratara de un triunfo internacional de toda sociedad chilena.

La prensa escrita dedicó a aquellos triunfos deportivos múltiples noticias que fueron incrementando, tanto a nivel cuantitativo, como a nivel cualitativo. La prensa agasajó y celebró el triunfo Olímpico de Atenas 2004, sin embrago, se encontraron escasos titulares que hicieran referencia al nacionalismo con el cual el pueblo chileno se identificó y celebró dicho hito olímpico.

Contrastando los resultados, no hemos apreciado un paralelismo significativo entre la leve orientación nacionalista de la prensa escrita y la identificación nacionalista que sí hemos encontradas a partir del testimonio de las fuentes orales.

\section{Fuentes y Bibliografía}

\subsection{Fuentes Primarias}

- Matías Vergara Soria, profesor chileno del área de Educación Física y salud. Egresado de la Universidad Bernardo O’higgins de Chile. En la actualidad es profesor en el Colegio Internacional SEK, además de entrenador de baloncesto del Club deportivo Universidad de Chile en la categoría Damas Infantil. Entrevista realizada en Madrid el día 10 de mayo del 2017.

- Álvaro Lagos Lagos, profesor chileno del área de Educación Física y salud. Licenciado en la Universidad Andrés Bello de Chile. Entrevista realizada en Madrid el día 10 de mayo del 2017.

- Edson García Díaz profesor chileno del área de Educación Física y salud. Entrevista realizada en Madrid el día 20 de mayo del 2017.

\subsection{Fuentes hemerográficas}

- $\quad$ Periódico El Mercurio de enero a diciembre del año 2004

- Periódico La Tercera de enero a diciembre del año 2004 
- Periódico Las Últimas Noticias de enero a diciembre del año 2004

- Periódico La Cuarta de enero a diciembre del año 2004

- (24 de agosto de 2004). El chileno Massú se abona el oro al ganar a Mardy Fish. El Mundo. Recuperado de http://www.elmundo.es/jjoo/2004/2004/08/22/masdeportes/1093209105.html

- (27 de agosto de 2013). Nicolás Massú, la historia de un gladiador olímpico que llego desde Viña del Mar. Recuperado de http://www.emol.com/noticias/deportes/2013/08/27/616571/nicolas-massu-un-heroe-olimpicoque-llego-desde-vina-del-mar.html

- González, C. (01 de septiembre de 2013). Un viaje a los orígenes de Nicolás Massú. La Tercera. Recuperado de http://www.latercera.com/noticia/un-viaje-a-los-origenes-de-nicolas$\underline{\text { massu/ }}$

- Massu Tenis. (2017). Nicolás Massú - Massu Tenis. [online]: Recuperado de http://www.massutenis.com/massu_tenis/nicolas-massu/.

- Mayo, A. (21 de agosto de 2013). Recuerda el primer oro olímpico de Chile a nueve años de la hazaña de Massú y González. La Tercera. Recuperado de http://www.latercera.com/noticia/recuerda-el-primer-oro-olimpico-de-chile-a-nueve-anos-de-lahazana-de-massu-y-gonzalezl

\subsection{Bibliografía}

- Abdón Mateos. (1998). Historia, Memoria, Tiempo Presente. Hispania Nova (1). Recuperado de http://hispanianova.rediris.es/general/articulo/004/art004.htm

- Bédarida, F. (1998). Definición, método y práctica de la Historia del Tiempo Presente. Cuadernos de Historia Contemporánea, 20, 19-27.

- Cavalla, M. (2006). Historia del tenis en Chile, 1882-2006. Ocho Libros Editores. Santiago.

- Fazio Vengoa, H. (1998). La historia del tiempo presente: una historia en construcción. Historia Crítica, (17) 47-57. Recuperado de http://www.redalyc.org/articulo.oa?id=81111329004 https://doi.org/10.7440/histcrit17.1998.04

- Hammer, D. y Wildavsky, A. (1990). La entrevista semi-estructurada de final abierto. Aproximación a una guía operativa. Historia y Fuente Oral, (4), 23-61.

- Martínez Gorroño, M.E. (1990). Fuentes orales para una aproximación al exilio femenino en Colombia. Espacio, Tiempo y Forma. Serie V. Historia Contemporánea. Serie V, n³, 2. ISSN 1130-0124, pp.85-106.

- Martínez Gorroño, M. E. (1996). Metodología y fuentes en el estudio del exilio español en Colombia a consecuencia de la guerra civil 1936-1939. En Trujillano Sánchez J. M. y Díaz Sánchez P. Actas y Jornadas Historia y Fuentes orales-testimonios orales y escritos (pp. 253258). Ávila, España: Fundación Cultural Santa Teresa. 
- Mudrovcic. (1998). Algunas consideraciones epistemológicas para una "historia del presente". Hispania Nova (1) Recuperado de:

http://hispanianova.rediris.es/general/articulo/013/art013.htm

- Soto Gamboa, A. (2004). Historia del presente: estado de la cuestión y conceptualización. HAOL (3) 101-116. Recuperado de: http://dialnet.unirioja.es/descarga/articulo/829443.pdf

- Sauvage, P. (1988). Una historia del tiempo presente. Historia Crítica (17) 59-70. Recuperado de: http://www.redalyc.org/articulo.oa?id=811113290045 